\title{
Is FirstSearch really attractive?
}

\author{
By Usha Gupta and Lutishoor Salisbury
}

\section{This service could be the answer to your patrons' information needs}

irstSearch, an inexpensive online interactive search service geared to end-user searching was recently introduced by OCLC. It contains 17 databases with 15 to be added by the end of 1992. FirstSearch can be accessed using OCLC workstations or terminals on many other microcomputers and terminals via dial access, dedicated line, or Internet communications.

This paper examines FirstSearch features and offers observations based on our month's free trial of FirstSearch at the University of Arkansas at Fayetteville. This service was made available to graduate students and faculty during February 1992. Passwords were provided to patrons interested in searching the databases through their personal computers on the internet. Mediated searches for patrons requesting this service were conducted by librarians.

\section{Costs}

FirstSearch allows patrons to control costs by charging by the number of search statements and not by connect hour or by records printed or displayed. Libraries may purchase searches in blocks of 500; the more searches purchased the cheaper the cost per search. Searches are always less than a dollar per search with prices varying from 45 to 90 cents per search statement. However, the lack of the Boolean operand "OR" can cause costs to mount. Based on 20 information requests conducted in Biosis/ FS for end users, a typical search had to be executed six times to allow for all the synonyms at a cost of $\$ 2.70-\$ 5.40$. Although the actual cost in dollars of a search is still relatively low, the search becomes more expensive if searchers factor in their time. Records can only be viewed/printed or downloaded one at a time so the time spent in viewing/printing/downloading can be considerable.

FirstSearch Card Authorizations can be sold or distributed free of charge, in batches of 10 to 25 searches, to library patrons enabling them to have individualized access. Users can keep track of how many searches are remaining on their accounts by checking the FirstSearch Administrator online every morning. The Administrator will indicate the number of remaining searches in the accounts by subtracting the number of search statements used during the day.

The Administrator would be more helpful to large libraries if the accounting software was interactive-subtracting the number of searches as they are used rather than once a day. Currently the system is updated once a day so searchers can use up their searches without realizing it. This can cause endless frustration to those searchers at remote sites who did not realize they should have purchased more searches for their account. Making the Administrator interactive would enable patrons to know how many searches they have used and the cost of the search at the end of the transaction.

Patrons can also control cost(s) if the limits for time, language, and formats are set at the outset. This is billed as one search statement. However, if the limits are applied during the process of searching, costs are incurred for each limit set (i.e., three search statements). If one has the patience for a few search statements, one could retrieve relevant information that would cost a considerable sum of money through other vendors. 
If the search term results in zero postings, there is no charge. For example, a misspelled entry "Arknsas" might get no postings, and therefore would not count as a search. However, two terms might have individual postings, but combining them with an AND operation might result in no hits. For example, "Basketball" might get 20 hits and "Daffodils" 12 hits but the search "Basketball AND Daffodils" might get zero hits; because both terms are posted in the database, the search counts and the searcher is charged. There is no charge for browsing the index, which is useful for preparation of a search strategy. For example, a patron looking for subject information could first browse the word index ( $w$ sh $=$ ) to see the number of entries and then decide if a search is worthwhile.

\section{Databases on CD-ROM vs. FirstSearch}

Most of the databases on FirstSearch are also available on CD-ROM products so libraries will have to examine which medium best meets their needs and budgets. FirstSearch does offer several advantages over the comparable CD-ROM products: 1) databases used infrequently may be cheaper to access on FirstSearch; 2) FirstSearch allows simultaneous access by multiple users; and 3) databases on FirstSearch are updated more frequently than similar databases on CD-ROM and, in some cases, have broader coverage than their print or CD-ROM counterparts. For example, Newspaper Abstracts on FirstSearch lists 25 titles while Newspaper $A b$ stracts on CD-ROM (UMI) has eight; the FirstSearch database is updated weekly and the CD-ROM monthly.

\section{WorldCar}

WorldCat (OCLC's union catalog with subject access) was popular with our patrons. This database has 24 million records for books (theses, dissertations, honors papers), journal titles, tapes, musical scores, sound recordings, films, videocassettes, computer programs, maps, and manuscripts. Patrons so far have not had access to a database of this size and the variety of formats at an affordable price through any of the online vendors. ${ }^{1}$ This database is especially useful for searching for theses and dissertations, honors papers, working papers, and internal reports emanating from individual universities, research stations, businesses, and corporations without the normal wide channels of distribution. Location symbols for libraries are provided expediting interlibrary loan.
Libraries catalog theses and dissertations as soon as they are available and input the data into WorldCat. The currency and scope of coverage of theses (master's and doctoral) far exceeds that available in Dissertation Abstracts Intemational. ${ }^{2}$ There are 2,241,759 dissertations/theses listed in WorldCat while there are 1,085,142 in Dissertation Abstracts International. ${ }^{3}$ However, it should be noted that there might be duplicate records for some theses in WorldCat because separate bibliographic records for microfilm and paper copies are created. WorldCat is also a cheap source for finding titles in series; for verification of bibliographic references, for building comparative collections, and for compilation of bibliographies.

While recognizing that searching by holdings is very costly in terms of space for indexing the holdings field, WorldCat could offer a real service if it was enhanced with the ability to search by holdings. Libraries could access specific collections for universities with similar academic programs and use this valuable information in collection development. This can be done at present by the very tedious process of searching by subject and viewing the records for library holdings; call number ranges are not searchable. Smaller libraries would benefit from using WorldCat as their online catalog at much lower cost than automating their collections in terms of software, hardware, manpower, etc. Of course, OCLC will have to set a pricing policy for this service to the mutual advantage of both parties.

\section{User friendliness}

FirstSearch may appear to the end user as an easy-to-use system. However, a critical analysis of some searching strategies and the records retrieved suggest that the searching characteristics need considerable improvement and explanation for end-user searching. For instance, retrieving records by author (au:John Smith) can lead to many false drops and user frustration. By using the au: method in searching, the name John could be retrieved from one individual's name and Smith from the name of another person. Records are also retrieved for John Smith where an adjacency is implied for the first and last name. The form of entry for an author (i.e., au=John Smith) explains that searching a name as a bound-phrase results in precision in search results. This is a flaw in the presentation of information for the end user. This is also true for subject searches. The fact 


\section{"FirstSearch}

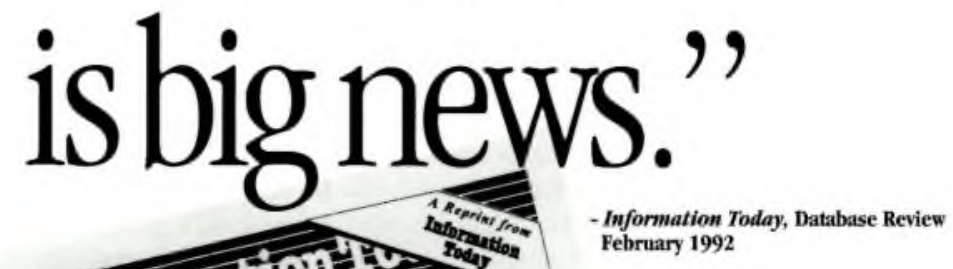

"[With FirstSearch,]

Database Review Takes the Lead

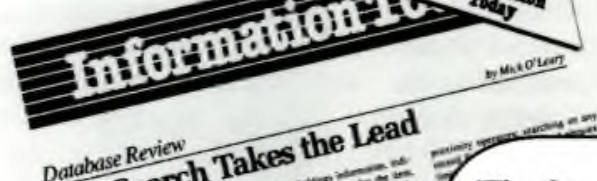

OCLC...has changed the whole online game."

"FirstSearch marks the Return of Online, because it can compete economically with a big set of CD-ROM databases, as well as providing online's advantages of currency, breadth, multiple access, and response time."

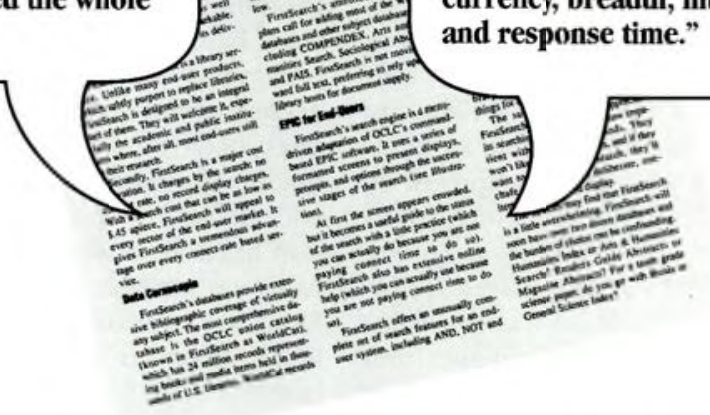

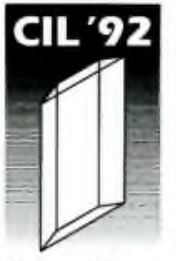

Meckler Information Product/Service Aword
Of course you've noticed there's a lot of interest these days in expanding patron access to online databases. In case you haven't noticed, that's created a lot of interest in The FirstSearch

\section{Catalog.}

"FirstSearch Takes the Lead"

in economy, currency, and breadth of information with a growing list of popular databases including PsycINF0, ContentsFinder and ArticleFinder (serials table of contents), Readers' Guide, Newspaper Abstracts and more.
To find out more about why award-winning FirstSearch is making headlines, contact your OCLC-affiliated Regional Network or call OCLC Field Marketing Services at these toll-free numbers:

\section{1-800-848-5878 (U.S. and Canada)} 1-800-848-8286 (Ohio)

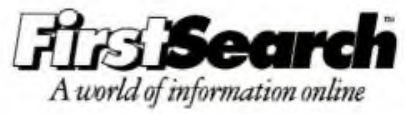


that Su: searches target references from the title, subject, and series field results in retrieving irrelevant records. Further, end users do not have access to thesaurus and subject headings lists and therefore would expect the word list to be much more comprehensive. The online help screens need to be transparent to users for important search concepts. End users should be provided with one definitive method of searching a field which would result in retrieval of relevant references.

\section{Conclusion}

FirstSearch offers an inexpensive and attractive service. It has very good potential as an end-user resource but attention needs to be directed towards improving the searching characteristics and its method of viewing/printing/ downloading. With the availability of WorldCat, BIOSIS/FS, and the Wilson databases at a very affordable pricing policy, together with location symbols to aid in document delivery, this service could very well be the answer to many of our patrons' information problems.

1"Why Use DB23 on EPIC When We Have LC MARC?" OCLC Reference News (January/February 1992): p. 7

${ }^{2}$ Lutishoor Salisbury and Usha Gupta, FirstSearch: Potential and Search Characteristics (Submitted for publication, 1992), p. 3.

${ }^{3}$ Dialog Database Catalog 1991, p. 40.

\section{UC tries Firstsearch}

OCLC offered free public access to its FirstSearch service to the Davis, Irvine, Los Angeles, and San Diego campuses of the University of California (UC) during February 1992. FirstSearch was made available to library users without additional equipment by providing an INTERNET connection to FirstSearch via the MELVYL Library System. The ten-year-old MELVYL is a shared UC information system and includes the nine-campus union catalog, six article databases, and automatic INTERNET connections to about 30 library information systems worldwide.

Starting the second week of February, public access was offered to the four campuses as a menu choice through the UC MELVYL Library System. Remote or modem access was provided to selected users and OCLC provided stacks of coupons, good for ten searches, to distribute to UC users who wanted to have dial-up access from homes, offices, or dormitory rooms.

Librarians from the four campuses held a brief meeting on April 1 and shared the following observations. Although the librarians were concerned that one month was not sufficient time to evaluate a multiple database system such as FirstSearch, users were enthusiastic. They liked the menu-driven system with excellent help screens; most people were able to find something on the first try. Some faculty found the menu-driven system frustrating and were annoyed with the software barrier that prohibits the continuous printing or downloading of records. Connections were not always stable and during peak loads remote users reported being frequently dropped. There was little or no impact on staff at public service desks. The staff liked the ability to control which databases are available to users. For example, if ERIC was available in the library as a CDROM, access to ERIC FirstSearch could be blocked.

During the February trial period 8,099 searches were performed on the 14 databases on FirstSearch, as compared to 1,564,274 MELVYL catalog searches. WorldCat was the most frequently selected database with 3,511 searches. Some librarians thought this was because WorldCat was the first choice on the menu in all the subject categories. The article databases were searched 4,588 times and all files showed some use. Among the article databases, BIOSIS was the most popular followed by News, Humanities Index, Periodical Abstracts, and PAIS.

FirstSearch was a success and worth consideration for librarians who are looking for ways to increase access to the journal literature without local tapeloading.-James E. Crooks, data services coordinator, University of California, Irvine; bitnet: JECROOKS@UCI 